\title{
MENTAL STRESS DECREASES WITH OLDER AGE IN KARACHI, PAKISTAN.
}

\author{
Kisa Fatima Altaf', Shamoon Noushad ${ }^{1}$, Syed Zain Azher'\& Sadaf Ahmed ${ }^{1 \& 2}$ \\ 1. Advance Educational Institute and Research Centre. \\ 2. University of Karachi. \\ Corresponding Author Email: canceria3791@gmail.com
}

\begin{abstract}
Mental Stress is a Kind of mental revival or strain that can be aroused by a number of mental tasks-e.g., mental arithmetic, maze solving or a mentally troubled condition is called the mental stress. Major life events as changes in work, financial problems, studies load, children and family problems are few of these. Mental stress is seen to affect parts of the brain where thoughts, approach, speculation and decision making are processed through and stored along with basic motor activities. Constant exposure to mental stress hormones, whether it occurs during the upbringing, teenage years, old age, has an impact on brain structures involved in cognition and mental fitness. The WHO suggests that there can be "no health without mental health". People in many countries are exposed to harmful stress that leads to an augment in mental stress. The purpose of this study is to evaluate the cause of mental stress in Karachi population through Sadaf stress scale (SSS); various stressors may contribute to these mental stresses. The data was collected from different areas of Karachi .Sadaf stress scale (SSS) was used as an instrument for evaluation of mental stress. Results demonstrates that in age 20 and less shows $16.0 \%$ mild level of stress, in age 20 to 30 shows $24.0 \%$ mild level of stress, in age 30 to 40 shows $5.0 \%$ mild level of stress however 40 and greater age shows no stress levels. The hypothesis that mental stress responses are associated with age and gender was investigated.
\end{abstract}

\section{KEYWORDS}

Mental stress, Stress, Sadaf Stress Scale, Pakistan

\section{INTRODUCTION}

Everyone knows what stress is and no-one knows what it is (Selye, 1973). The WHO proposition that there can be "no health without mental health" (Prince, 2007).It has become a new lifestyle disease (Sweth, 2012). "Stress resides neither in the environment nor in the person; it depends on a connection between the both" (Richard, 1966). Mental Stress is a Kind of mental arousal or pressure or a mentally troubled condition is called the mental stress (Semrau, 2011). People in many countries are exposed to harmful stress that leads to an augment in mental stress. For many years, organizational research has focused on demonstrating relations between situational stressors, such as job demands and experienced strain (Beehr, 1995; Jex, 2001). The overall structure is a whole set of events and biological changes with respect to have the capability to react to stressors (Anisman, 1999), A variety of "stressors" (such as sentimental upsets, exposure to extremes of climate, and anoxia) set into motion defense reactions mediated through the nervous and the hormonal systems. These affect blood pressure, body temperature, blood sugar level, blood clotting, osmotic pressure and tissue hydration. During delay, acute systemic stress there are 3 phases: "shock," adaptation, and exhaustion (Selye, 1950).

\section{METHODOLOGY}

The study design was cross sectional, done on the population consists of 370 citizens of Karachi (Pakistan) from the age group of 13-50 years with different fields, most of them belonging to middle class families. Age groups $<13$ were excluded in this part of study. Data was collected randomly from different colleges \& universities and areas of Karachi, on a questionnaire based Performa, and analyzed by Sadaf Stress Scale (SSS) on excel 2007 and SPSS 20.0 format. Frequencies, percentages, means and standard deviations were also employed in analyzing the data.

\section{RESULTS}

The results brought to light a few areas of concern that need to be taken into consideration, it demonstrates that in age 20 and less shows $16.0 \%$ mild level of stress, in age 20 to 30 shows $24.0 \%$ mild level of stress, in age 30 to 40 shows $5.0 \%$ mild level of stress however 40 and greater age shows no stress levels, according to gender males having $13.9 \%$ mild and $1.7 \%$ severe whereas in females $11.4 \%$ mild and $2.4 \%$ severe (as shown in the figure below). The hypothesis that mental stress responses are associated with age and gender was investigated.

\begin{tabular}{|cc|c|c|c|c|}
\hline & Frequency & Percent & Valid Percent & Cumulative Percent \\
\hline \multirow{4}{*}{ Valid } & Normal & 306 & 82.7 & 82.7 & 82.7 \\
& Mild & 45 & 12.2 & 12.2 & 94.9 \\
& Moderate & 11 & 3.0 & 3.0 & 97.8 \\
& Severe & 8 & 2.2 & 2.2 & 100.0 \\
& Total & 370 & 100.0 & 100.0 & \\
\hline
\end{tabular}




\begin{tabular}{|ll|r|r|r|r|r|}
\hline & \multicolumn{4}{|c|}{ Mental Stress } & \multirow{2}{*}{ Total } \\
\cline { 3 - 7 } & \multicolumn{1}{|c|}{ Normal } & Mild & Moderate & \multicolumn{1}{c|}{ Severe } & \\
\hline \multirow{4}{*}{ Age in Years } & 20 and less & 95 & 16 & 7 & 3 & 121 \\
& $20-30$ & 78 & 24 & 1 & 0 & 103 \\
& $30-40$ & 105 & 5 & 3 & 5 & 118 \\
Total & 40 and greater & 28 & 0 & 0 & 0 & 28 \\
\hline
\end{tabular}

\section{\% within Gender}

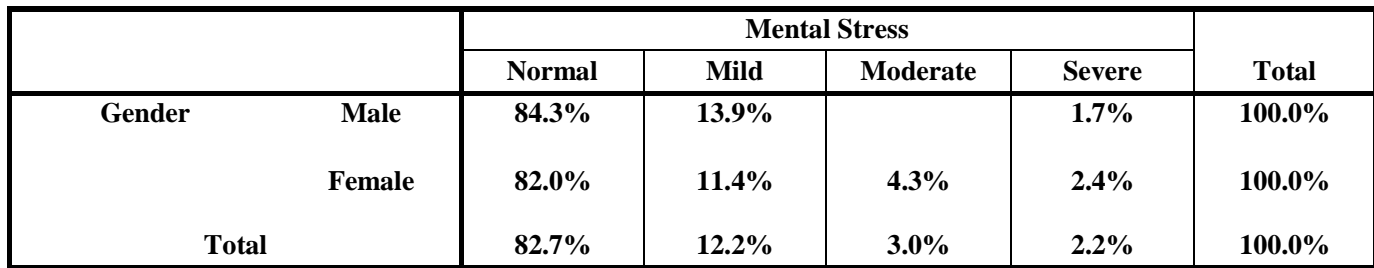

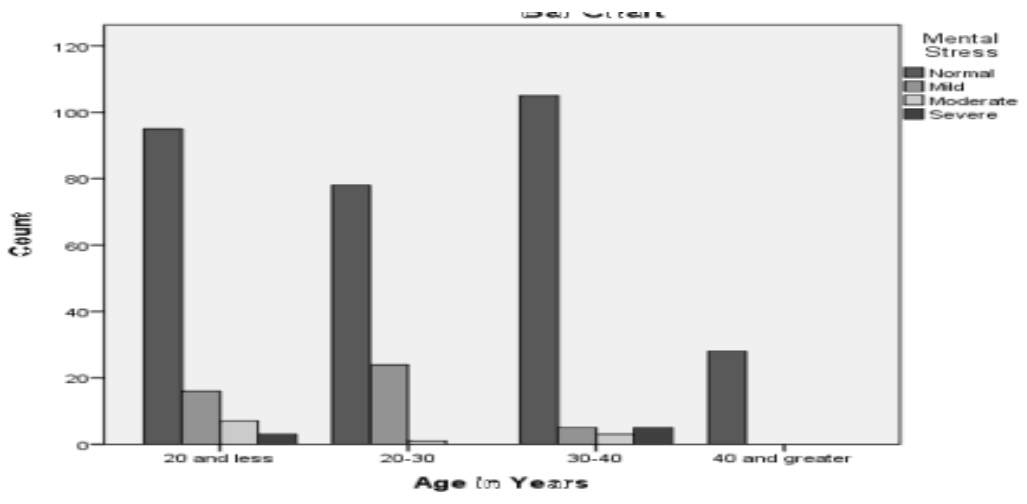

Graph: 1 shows the mental stress level according to Age

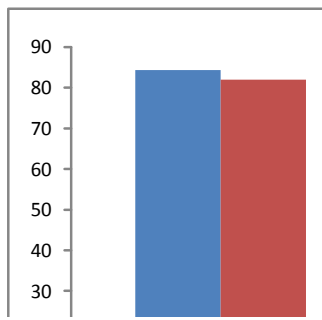

Graph 2: Shows the mental stress level according to gender

\section{DISCUSSION}

A state of affairs, circumstances, or any stimulant that is recognized to be an intimidation is referred to as a stressor or those which causes or endorse stress (Seaward, 2013). Multilevel figures specify that on days when people experienced stressors, particularly interpersonal stressors, they were more likely to report memory failures. These stressors were also correlated with an increase in memory failures from day by day (Neupert, 2006).Stressors can be broken down roughly into either external or internal (or a mixture of both) (Levins, 1998). There are uncounted origin of stress known as stressors (Lazarus, 1986).Positive \& negative (Sadaf, 2013). Low socio-economical status, low educational level and stress and distress cause adverse effect on memory and mental function (Shamoon, 2012). According to a 2006 Mayo Clinic study, students enter medical school with mental health profiles similar to their peers from college. But they begin to show higher rates of mental distress as they progress through medical school. The same study found that the most depressed students often are the least likely to reach out for help because of stigma related to mental illness. This study shows that people from age group 20-30 are more likely to be in mental stress due to their tough academic schedule or freshly employed and they are not taking of time for their own hobbies to get relieved from further 
stresses. People can't even take part in co-curricular activities or for physical fitness because of lack of time due to their academic schedule or lack of interest (Maria, 2013).

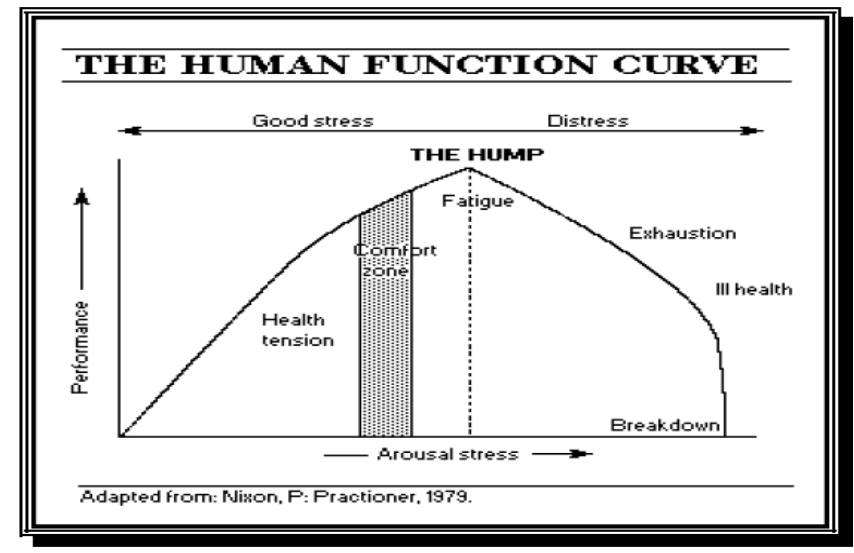

Hens Syele developed a model called the General Adaptive Syndrome Model to explain the stress phenomenon and the stress level. This model has four stages. The first stage is the alarm reaction stage, which involves the body's response to or familiarizing itself with the new situation or stressor. The second stage is the resistance stage, which involves resisting and reacting to the situation, and the third stage is exhaustion stage, Which is aftermath of resistance. If the resistance stage goes for a long period, then the person becomes distressed. Fourth stage is Termination, if there is no relief from arousal, and then the stress on the physiological system can lead to death.

\section{CONCLUSION}

There is some implication that elderly is linked with necessary decrease in susceptibility to mental stress. However, some studies revealed that aging is associated with mental stress. More consideration needs to be given to understanding the mechanism behind any ageing-related reduction in risk for mental stress with age. Keep in mind that the signs and symptoms of stress can also

\section{REFERENCES}

- Anisman, H., \& Merali, Z. (1999). Understanding stress: characteristics and caveats. Alcohol Research and Health, 23(4), 241-249.

- Beehr, T. A. (1995). Psychological stress in the workplace. London: Routledge.

- Jex, M. S., Bliese, P. D., Buzzell, S., \& Primeau, S. B. 2001. The impact of self-efficacy on stressor-strain relations: Coping style as an explanatory mechanism. Journal of Applied Psychology, 86(3): 401-409.

- Lazarus, R. S., \& Folkman, S. (1986). Cognitive theories of stress and the issue of circularity. In Dynamics of stress (pp.6380). Springer US

- Levins, R. (1998). The internal and external in explanatory theories. Science as Culture, 7(4), 557-582.

- Maria altaf. \& Kisa Fatima. (2013). Increasing obesity and its risk factors. Int. j. endorsing health sci. res.2 (1).21-24.

- Neupert, S. D., Almeida, D. M., Mroczek, D. K., \& Spiro III, A. (2006). Daily stressors and memory failures in a naturalistic setting: findings from the VA Normative Aging Study. Psychology and aging, 21(2), 424. be caused by other psychological and medical problems. If you're experiencing any of the warning signs of stress, it's important to see a doctor for a full evaluation. Your doctor can help you determine whether or not your symptoms are stress-related. Mental health awareness needs to be integrated into all aspects of health and social policy, health system planning, and delivery of primary and secondary general health care.

- Prince, M., Patel, V., Saxena, S., Maj, M., Maselko, J., Phillips, M. R., \& Rahman, A. (2007). No health without mental health. The Lancet, 370(9590), 859-877.-0

- Sadaf, A. \& Shamoon, N. (2013). Sorts and sources of stress in Pakistan; A Comprehensive outlook. Int. j. endorsing health sci. res. 1(1).

- Seaward, B. L. (2013). Essentials of managing stress. Jones \& Bartlett Publishers.

- Selye, H. (1950). The physiology and pathology of exposure to stress.

- Selye, H. (1973). The Evolution of the Stress Concept: The originator of the concept traces its development from the discovery in 1936 of the alarm reaction to modern therapeutic applications of syntoxic and catatoxichormones.American scientist, 61(6), 692-699.

- Semrau, M., Barley, E. A., Law, A., \&Thornicroft, G. (2011). Lessons learned in developing community mental health care in Europe. World Psychiatry, 10(3), 217-225

- Shamoon, N. \& Sadaf, A. Effect of exercise on hematological paramaters; a study on trained vs un-trained male subjects. Pak. j. life soc. Sci. (2012), 10(1): 18-21.

- Sweth, S. (2012) "stress management-an overview" human resource topic paper presentation. Institute of Aeronautical Engineering, Dundigal. 
Print: ISSN 2307-3748

Online: ISSN 2310-3841 